\title{
Cable Force Adjustment of Torsion Cable-Stayed Bridge
}

\section{Li Cai}

Shandong Transportation Institute, Jinan, China

Email address:

\section{To cite this article:}

Li Cai. Cable Force Adjustment of Torsion Cable-Stayed Bridge. Journal of Civil, Construction and Environmental Engineering.

Vol. 3, No. 4, 2018, pp. 106-110. doi: 10.11648/j.jccee.20180304.12

Received: August 10, 2018; Accepted: August 24, 2018; Published: September 19, 2018

\begin{abstract}
Cable force adjustment of cable-stayed bridge has been a hotspot. The structure of the cable-stayed bridge is more complicated, and its cable force adjustment method is also difficult. In order to explore the reasonable method to adjust the cable force of the torsion cable-stayed Bridges, this paper discusses the objectives and principles of cable tension adjustment. The influence matrix method and the finite element analysis software midas civil 2012 of bridge structure are used to design the scheme. The cable adjustment scheme is developed by using the trial algorithm, and the cable adjustment effect is analyzed. Firstly, influence matrix method was used to analyze the mutual influence degree between adjacent cables. Then the adjusting value of cable force is calculated by iteration until convergence. Input the adjustment values of each step into the finite element analysis software to analyze the adjustment process and results The whole bridge is monitored and measured in the course of cable adjustment. The monitoring results show that the cable force is close to the target value after the adjustment of the cable force. The alignment of bridge deck after adjustment is also in good agreement with the design, and the deflection of tower top is improved. This practice will provide a more important reference for similar project.
\end{abstract}

Keywords: Cable-Stayed Bridge, Cable Force Adjustment, Twisting Cable Plane, Influence Matrix, Midas

\section{Introduction}

The cable-stayed bridge has a superior structure bearing system and a beautiful shape, mainly composed of main towers, girders and cables. [1-3] The cable force adjustment of cable-stayed bridges has always been a research hotspot. A cable-stayed bridge includes multiple cables. A change of force in a cable affects other cables. Therefore, when adjusting the cable force of a cable-stayed bridge, we should consider the full bridge. [4-6] The calculation methods for the cable force adjustment of cable-stayed bridges mainly include influence matrix method, approximation method, mathematical programming method, etc, [4-8] these methods have their own characteristics and applicability, and should be adjusted repeatedly according to the specific bridges and tests in practical applications. [6-8] Torsion cable plane means that the cable stays in a torsionally curved plane. The longest cable stays at the lowest anchor position on the tower, while the shortest cable has the highest anchor position on the tower. In this paper, combined with the practice of cable force adjustment of cable-stayed bridges with Torsion cable plane and steel box girder, the objectives and principles of cable force adjustment are described. The finite element analysis software of bridge structure Midas Civil 2012 and the trial algorithm is used to formulate the adjusting scheme. Monitor the adjusting process and analyze the adjusting effect.

\section{Project Overview}

The Ji canal bridge in Tianjin is a cable-stayed bridge with torsion cable - plane, which has two spans and one main tower. The main girder is made of steel box. Cross-border layout of the bridge is $2 \times 118 \mathrm{~m}$. The main bridge structure adopts a semi-float structure system, and the main tower and the main pier are fixed. The total height of the bridge tower is $91.5 \mathrm{~m}$. The main tower is composed of steel towers and concrete towers. It is divided into tower top, steel tower, steel-concrete section tower, and concrete tower. The foundation is the pile foundation. A total of $4 \times 13$ cable stays are provided for the entire bridge. One side of cable stays is anchored on the tower and one side is anchored on the outer side of the steel box girder web. The anchorage ends of the stay cables are located on the webs of the chambers on both sides of the steel tower, the vertical distance is $2.5 \mathrm{~m}$. Design the vehicle load: City-A, crowd load $3.5 \mathrm{kPa}$. The elevation of Ji canal bridge is shown 
in Figure 1.

2015-01-06, after the completion of the tensioning of the bridge cable, it was found that the elevation of the bridge surface did not reach the expected value. The measurement results of the cable force measurement instrument showed that the cable force of the entire bridge did not reach the expected value. It was due to the frictional resistance that caused the tensile jack oil. The reading of the gauge is not accurate, resulting in insufficient tension. In order to achieve the expected values of cable force and bridge deck elevation, it is necessary to adjust the cable force. The cable number is: $\mathrm{S} 1 \sim \mathrm{S} 13$ from the main tower to the shore in the south span, and S1' S13' from the main tower to the shore in the north span. The comparison of the cable force after the first tension is completed and the expected value is shown in Table 1.

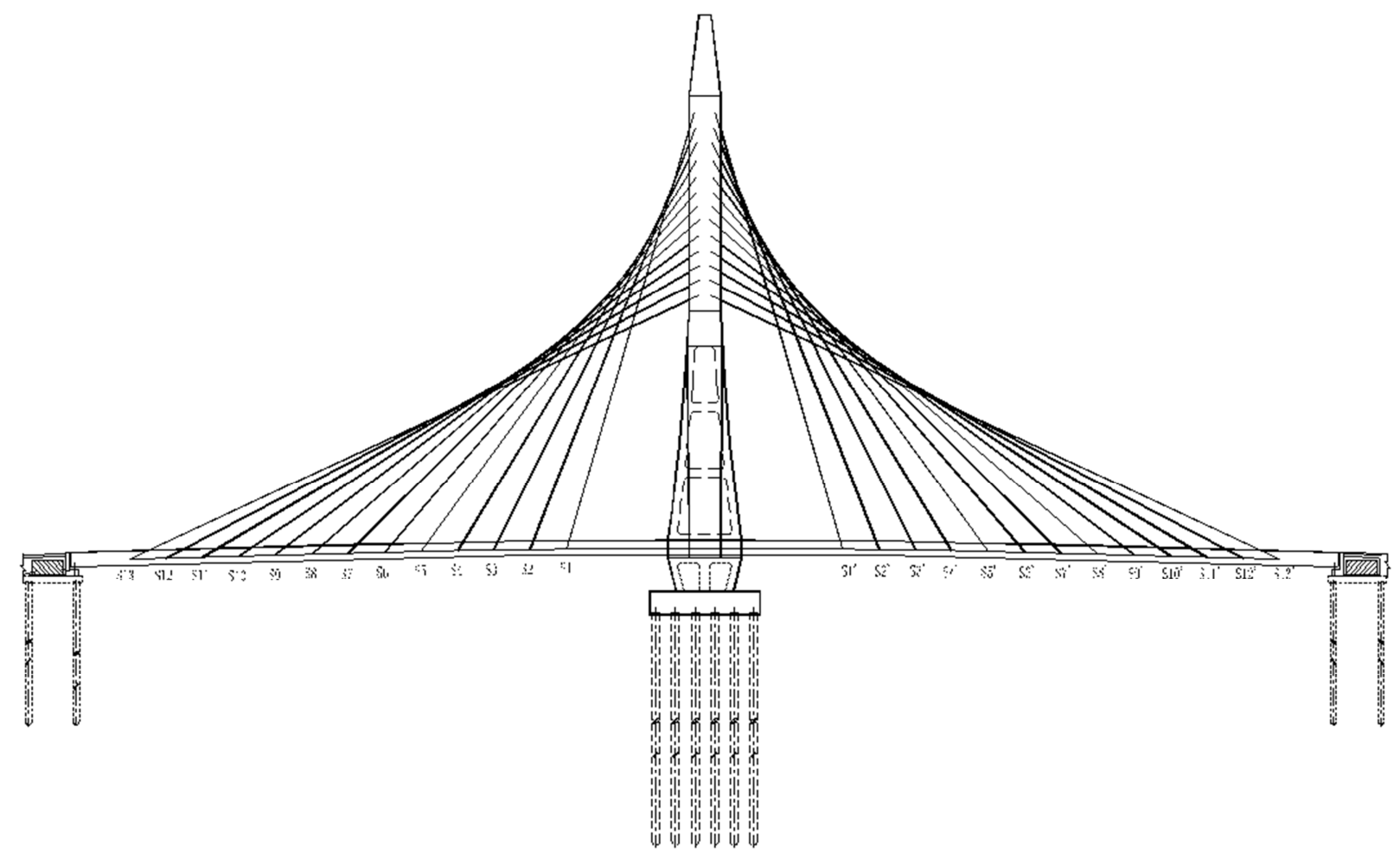

Figure 1. Elevation of the Ji canal bridge.

Table 1. The cable force after the first tension is completed $k N$.

\begin{tabular}{|c|c|c|c|c|c|}
\hline \multirow{2}{*}{ number } & \multirow{2}{*}{ calculating cable force } & \multicolumn{2}{|c|}{ measured cable force } & \multicolumn{2}{|l|}{ Difference } \\
\hline & & Upstream side & Downstream side & Upstream side & Downstream side \\
\hline $\mathrm{S}_{13}$, & 2884 & 2966 & 2869 & 82 & -15 \\
\hline $\mathrm{S}_{12}$ & 2620 & 2615 & 2673 & -5 & 53 \\
\hline $\mathrm{S}_{10}$, & 2059 & 1610 & 1543 & -449 & -516 \\
\hline $\mathrm{S}_{9}$ & 1638 & 1571 & 1559 & -67 & -79 \\
\hline $\mathrm{S}_{8}$ & 1408 & 1196 & 1144 & -212 & -264 \\
\hline $\mathrm{S}_{7}$ & 1354 & 1314 & 1225 & -40 & -129 \\
\hline $\mathrm{S}_{5}$ & 1400 & 1290 & 1203 & -110 & -197 \\
\hline $\mathrm{S}_{4}$ & 1318 & 1174 & 1183 & -144 & -135 \\
\hline $\mathrm{S}_{3}$ & 1276 & 1218 & 1263 & -58 & -13 \\
\hline $\mathrm{S}_{2}$ & 1304 & 1047 & 1183 & -257 & -121 \\
\hline $\mathrm{S}_{1}$ & 1427 & 1261 & 1500 & -166 & 73 \\
\hline $\mathrm{S}_{1}$ & 1427 & 1349 & 1290 & -78 & -137 \\
\hline $\mathrm{S}_{2}$ & 1304 & 1084 & 1195 & -220 & -109 \\
\hline $\mathrm{S}_{3}$ & 1276 & 1246 & 1365 & -30 & 89 \\
\hline $\mathrm{S}_{5}$ & 1400 & 1079 & 1112 & -321 & -288 \\
\hline $\mathrm{S}_{6}$ & 1395 & 1570 & 1462 & 175 & 67 \\
\hline $\mathrm{S}_{7}$ & 1354 & 1446 & 1361 & 92 & 7 \\
\hline $\mathrm{S}_{8}$ & 1408 & 1276 & 1188 & -132 & -220 \\
\hline $\mathrm{S}_{9}$ & 1638 & 1722 & 1653 & 84 & 15 \\
\hline $\mathrm{S}_{10}$ & 2059 & 1553 & 1596 & -506 & -463 \\
\hline $\mathrm{S}_{11}$ & 2232 & 2299 & 2260 & 67 & 28 \\
\hline $\mathrm{S}_{12}$ & 2620 & 2726 & 2710 & 106 & 90 \\
\hline $\mathrm{S}_{13}$ & 2884 & 2970 & 2929 & 86 & 45 \\
\hline
\end{tabular}




\section{Cable Force Adjustment}

\subsection{Objectives and Principles}

The lack of cable force is the root cause of the full bridge deck mark being less than expected. For cable-stayed bridges, the stress state of the cables and the bridge line type can be changed by adjusting the cable force, so that the bridge structure achieves the best stress state and the line type is closer to the design line type. [9] The objective of this round of adjustment is: after the cable is adjusted, the difference between the total cable force and the target cable force is within $\pm 5 \%$, the deviation of the bridge surface elevation from the expected value is within $\pm 20 \mathrm{~mm}$.

The force adjustment should take into account the main beam type, main beam stress and tower deviation. [6] After the completion of the first tensioning, the overall elevation of the deck is much lower than the expected value. Therefore, the overall height of the deck should be increased after adjustment, and major changes in the main beam profile should be avoided to avoid excessive stress on the main beam. [10]

\subsection{Cable Force Adjustment Difficulties}

Twisted cable planes and plane cable planes are not only different in form, but their structures are also more complex. The main difficulties when adjusting cable forces are: 1) The cable lengths of torsion cables vary greatly. 2) The angle between the long cable and the deck is small. When the cable force changes, it has a great influence on the internal force of the girder. When adjusting the cable, the internal force of the girder must be taken into consideration. 3) A cable force adjustment has a great influence on the cable force of the full-bridge. It needs to iteratively calculate the cable force until it is closed.

\subsection{Cable Force Adjustment Program}

The finite element analysis software midas civil 2012 is used to build the bridge model. The main tower and the main beam are simulated by beam elements. Cables are simulated by cable elements. The whole bridge is divided into 73 beam elements and 52 cable elements. The calculation model is shown in Figure 2.

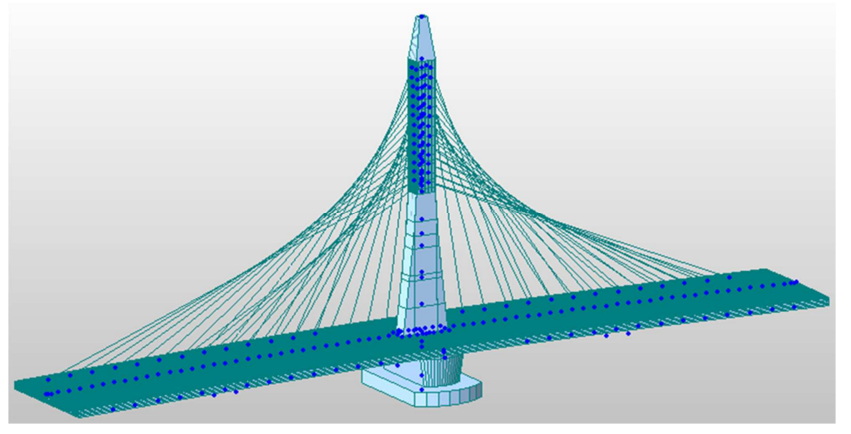

Figure 2. Calculation model.

In the calculation, firstly, influence matrix method was used to analyze the mutual influence degree between adjacent cables. The cable force of $100 \mathrm{kN}$ for each cable group was calculated and the influence of cable adjustment on other cables was analyzed. The analysis results show that the cable force adjustment has obvious influence on the cable forces of the three pairs of cables before and after the cable number, and the impact on other cables is negligible. With the cable tension after the first tensioning being the original state, using midas civil 2012 combined with iterative calculations to formulate adjusting sequences and adjustment values. The steps for iterative calculation are: (1) Apply half of the difference between the measured cable force of $1 \#$ cable and the target cable force to the corresponding cable, analyze the change of cable force of the full cable, and then adjust $2 \# \sim 13 \#$ in sequence by the same method. (2) Repeat step 1 until the full bridge cable force reaches the target value; (3) The cumulative adjustment of each cable is the cable force adjustment value at the time of adjusting. Cable force, bridge elevation and tower deviation are monitored during the cable adjustment process. The cable force monitoring in the cable adjustment process uses the cable force tester. Each adjustment of a set of cable forces compares the measured value with the calculated value. The value and its deviation, if the deviation is too large, should analyze the reason and adjust the adjusting plan in time. When adjusting, the same number of 4 strings are simultaneously symmetric. According to the calculation results, the adjusting procedure is as shown in Table 2. Note: The positive value of the adjustment value indicates the cable force to be added on the basis of the current cable force value, and the negative value indicates the cable force to be reduced. [11-12]

Table 2. Cable force adjustment steps.

\begin{tabular}{|c|c|c|c|}
\hline \multirow{2}{*}{$\begin{array}{l}\text { adjustment } \\
\text { steps }\end{array}$} & \multirow{2}{*}{ number } & \multicolumn{2}{|c|}{ adjustment value (kN) } \\
\hline & & Upstream side & Downstream side \\
\hline \multirow{2}{*}{1} & $\mathrm{~S} 1$ & 186 & 328 \\
\hline & $\mathrm{S} 1$ ' & 339 & 205 \\
\hline \multirow{2}{*}{2} & $\mathrm{~S} 2$ & 387 & 316 \\
\hline & $\mathrm{S} 2{ }^{\prime}$ & 461 & 414 \\
\hline \multirow{2}{*}{3} & $\mathrm{~S} 3$ & 253 & 192 \\
\hline & $\mathrm{S} 3{ }^{\prime}$ & 343 & 355 \\
\hline \multirow{2}{*}{4} & S4 & 415 & 466 \\
\hline & S4' & 486 & 532 \\
\hline \multirow{2}{*}{5} & S5 & 546 & 548 \\
\hline & S5 & 480 & 605 \\
\hline \multirow{2}{*}{6} & S6 & 118 & 273 \\
\hline & S6 & 289 & 435 \\
\hline \multirow{2}{*}{7} & S7 & 158 & 308 \\
\hline & $\mathrm{S} 7$ & 453 & 556 \\
\hline \multirow{2}{*}{8} & S8 & 384 & 490 \\
\hline & S8 & 581 & 643 \\
\hline \multirow{2}{*}{9} & S9 & 204 & 201 \\
\hline & S9' & 385 & 427 \\
\hline \multirow{2}{*}{10} & $\mathrm{~S} 10$ & 613 & 613 \\
\hline & S10' & 720 & 789 \\
\hline \multirow{2}{*}{11} & S11 & 59 & 99 \\
\hline & $\mathrm{S} 11$ & 170 & 166 \\
\hline \multirow{2}{*}{12} & $\mathrm{~S} 12$ & 3 & 62 \\
\hline & $\mathrm{S} 12$ & 232 & 181 \\
\hline \multirow{2}{*}{13} & $\mathrm{~S} 13$ & -29 & 62 \\
\hline & S13, & -37 & 14 \\
\hline
\end{tabular}

\subsection{Adjustment Effect Analysis}

In the process of cable adjustment, the changes of cable 
force, deck elevation and tower deviation were monitored, and the measured changes and calculated changes were compared and analyzed. The results showed that the changes of cable deck elevation and tower deviation were both in anticipation of Anastomosis. Changes in the structural state of the full bridge before and after adjustment are compared and analyzed.

\section{1) Full-bridge cable force}

After the adjustment is completed, the measured cable force is compared with the calculated cable force (see Figure 4). The results show that the cable force is in good agreement with the calculated value, and the deviation is within $\pm 5 \%$.

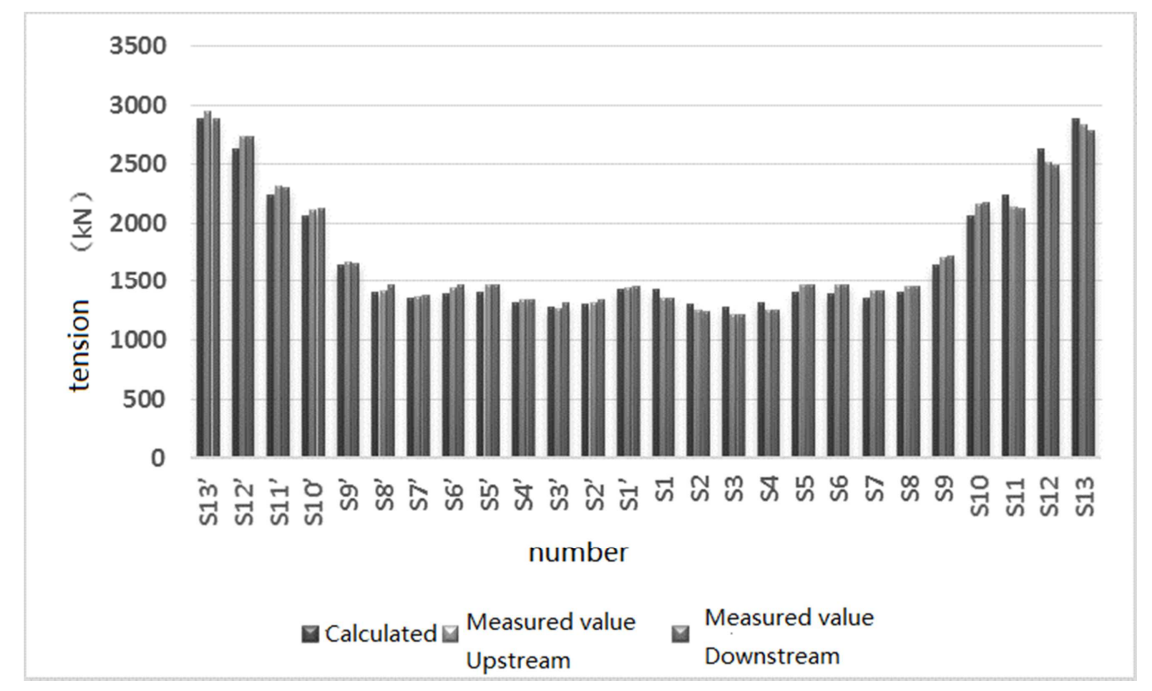

Figure 3. Comparison of measured and calculated values of cable force after cable adjustment.

\section{2) Bridge surface shape}

The change in the shape of the bridge surface is shown in Figure 5. From Figure 5, it can be seen that the alignment of the bridge shape is in good agreement with the expected value, so that the force of the main beam is more reasonable. After the cable adjustment, the total height of the deck elevation is raised. The maximum lifting amount is $92 \mathrm{~mm}$, which is on the downstream side of S7.

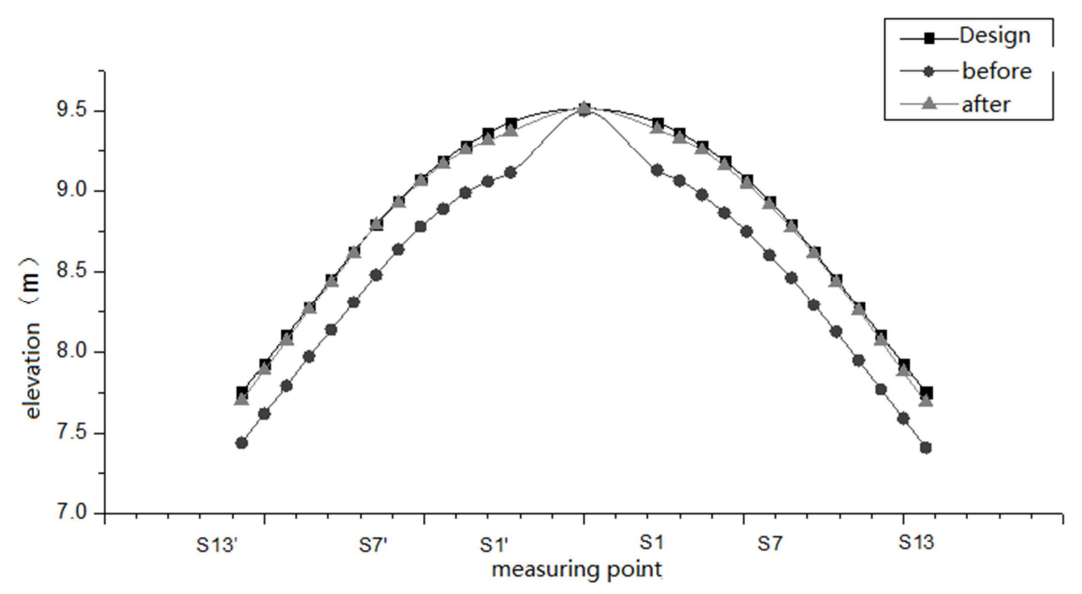

Figure 4. Changes in the shape of the bridge surface before and after cable adjustment.

\section{3) Tower top deviation}

The deviation of the tower is $28 \mathrm{~mm}$ for the longitudinal bridge before adjusting the cable, and there is no deviation in the horizontal bridge. After the adjustment, the deviation in the longitudinal bridge is $-14 \mathrm{~mm}$, and in the horizontal bridge is $13 \mathrm{~mm}$ to the right.

\section{Conclusion}

Through the practice of torsion cable-stayed bridges with steel cable girders in a single tower, the following conclusions can be drawn: (1) For the cable-stayed bridge with torsion cable plane whose main girder is a steel box girder, it is feasible to use the finite element analysis software of the bridge structure and iterative method to calculate the cable force adjustment value. (2) Due to the presence of frictional resistance, it is unreliable to control the cable force with the reading of the oil gauge of the tension jack, especially for cables with large inclination. (3) The cable force adjustment methods and engineering practices adopted in this paper have accumulated experience for cable tension adjustment of cable-stayed bridges and can serve as a reference for similar 
projects. (4) More accurate cable force detection technology remains to be studied.

\section{References}

[1] JIANG W, Research on Cable - changing Theory and Technical Problems of Cable - stayed Bridge[D].Chengdu: Southwest Jiaotong University, 2000.

[2] VIRLOGEUX M, Recent evolution of cable-stayed bridges[J]. Engineering Structures, vol.12(8),pp.737-755, 1999.

[3] JIA L, XIAO R, SUN B, et al, Influence Matrix Method for Determining Tensile Force of Cable - stayed Bridge[J]. Journal of Suzhou Urban Construction Environmental Protection College, vol.12(8), pp.737-755, 1999.

[4] XIAO R and XIANG H, Influence Matrix Method for Cable Force Optimization of Cable - Stayed Bridge[J]. Journal of Tongji University, vol.26 (3) , pp.235-240, 1998.

[5] DU P, ZHANG Z, LIU C, et al. Optimal Control of Cable Tensioning Process of Cable - Stayed Bridge [J]. Chinese Journal of Computational Mechanics, vol.22 (3) , pp.326-329, 2005.
[6] GUAN W and HAN D, Cable tension adjustment of cable stayed bridge[J]. Journal of Kunming University of Technology, vol.25(1), pp.125-128, 2000.

[7] WANG M, Adjustment of Cable Force and Optimization of Tuning Order of Hongfeng Lake Bridge[D].Dalian: Dalian University of Technology, 2005.

[8] FANG Z , WANG J and YAN J. Tension test of cable and boom based on frequency method $[\mathrm{J}]$. Vibration and shock, vol.26(9), pp.78-82, 2007.

[9] Chongqing transportation research and design institute, Guidelines for Design of Highway Cable-stayed Bridge: JTG/T D65-01-2007 [S]. Beijing: China Communications Press, 2007.

[10] HUANG C, BU Y. Discussion on the development of construction control method of cable-stayed bridge [J]. Sichuan Architecture sichuan architecture, vol.03,12-15, 2007.

[11] HUANG C, BU Y. Discussion on the development of construction control method of cable-stayed bridge [J]. Sichuan Architecture sichuan architecture, vol.03,12-15, 2007.

[12] LIU S. On the basic situation and development prospect of cable-stayed bridge [J]. Henan building materials, vol.05, 2016. 